\title{
School Based Development Of Scout Teachings
}

\author{
Paulus Rah Adi Pawitra', Trinovandhi Setyawan ${ }^{2)}$ \\ Program Studi Pedidikan Jasmani Kesehatan dan Rekreasi \\ Fakultas Pendidikan Ilmu Eksakta dan Keolahragaan \\ 1,2 IKIP Budi Utomo Malang \\ Email: ${ }^{1}$ super_paitro@yahoo.com, ${ }^{2}$ trinovandhisetyawan1986@gmail.com
}

\begin{abstract}
This development aims to produce a product of a scout textbook as part of an effort to create a fun and active learning process. This study uses a model of floating (Research and development) from Brog and Gall (in Winarno) includes the following stages: 1. Data collection, 2. Planning, 3. Developing products, 4. Small group testing, 5. Revision of the 1st product, 6. Large group test, 7. Revision of the second product, 8. Field testing, 9. Revision of the 3rd program, 10. Dissemination and implementation. The instruments are interviews and questionnaires. Quantitative and descriptive data analysis techniques "qualitative. The results of the validity of the content experts are $91.67 \%$, (very valid), Indonesian language experts $95 \%$ (Very Valid), learning media experts are $95 \%$ (very valid), Test "small" group is $94 \%$ (very valid), Big "group" test $94.5 \%$ (very valid), and field test of $95 \%$ (very valid). In the sense of scout textbooks on the qualification "Very feasible" is used. Making scout textbooks based on science can be used as a supporting medium in improving the quality of learning.
\end{abstract}

Keywords: Textbook, Scientific, Scout

\section{Pengembangan Buku Ajar Pramuka Berbasis Saintifik ABSTRAK}

Pengembangan ini bertujuan menghasilkan sebuah produk sebuah buku ajar pramuka sebagai bagian dari upaya menciptakan proses belajar yang menyenangkan dan aktif. Penelitian ini menggunakan model pengambangan (Research and development) dari Brog dan Gall Meliputi tahap: 1) Pengumpulan data, 2) Perencanaan, 3) Mengembangkan produk, 4) Uji kelompok kecil, 5) Revisi pertama, 6) Uji kelompok besar, 7. Revisi ke dua, 8) Uji lapangan, 9. Revisi ke tiga, 10. Diseminasi dan implementasi. Instrumen yang digunakan berupa wawancara dan angket terhadap 4 orang ahli, 10 subjek uji coba kelompok kecil, 30 subjek uji coba kelompok besar, 50 subjek uji lapangan. Teknik analisis data kuantitatif dan deskriptif kualitatif. Hasil validitas dari ahli isi sebesar 91,67\%, (sangat valid), ahli Bahasa Indonesia 95\% (Sangat Valid), ahli media pembelajaran sebesar 95\% (sangat valid), Uji kelompok keci sebesar 94\% (sangat valid), Uji kelompok besar 94,5\% (sangat valid), dan Uji lapangan sebesar 95\% (sangat valid). Dalam artian buku ajar pramuka pada kualifikasi "Sangat layak" digunakan. Menjadikan buku ajar pramuka berbasis saintifik telah dapat digunakan sebagai media penunjang dalam meningkatkan kualitas pembelajaran.

Kata Kunci: Buku Ajar, Saintifik, Pramuka

Info Artikel

Dikirim

Diterima

Dipublikasikan 


\section{PENDAHULUAN}

Salah satu komponen penting dalam sistem pendidikan nasional dalam memajukan ilmu pengetahuan, teknologi dan mencerdaskan kehidupan bangsa adalah perguruan tinggi, yang memiliki tanggungan untuk melaksanakan tridharma yang meliputi, pengajaran, penelitian, dan pengabdian pada masyarakat. Penelitian pendidikan dilakukan melalui pengembangan bahan ajar sebagai upaya dalam meningkatkan kualitas terkait proses mengajar dan belajar. Perguruan tinggi sebagai pendidikan formal diharapkan memberikan kontribusi lebih besar dalam upaya untuk meningkatkan ilmu pengetahuan dan teknologi bangsa terus berkembang sangat pesat, pada satu sisi perhatian pendidikan karakter mulai menurun, oleh karena itu salah satu pendidikan yang menawarkan nilai karakter adalah pendidikan pramuka, (Muhaemin \& Ihwah, 2019). Pendidikan bukan sekedar mengajarkan atau mentransfer pengetahuan atau semata mengembangkan aspek intelektual, melainkan juga mengembangkan karakter dan moral, (Cahyono et al., 2018) Pendidikan pramuka merupakan sistem pendidikan kepanduan yang diselaraskan dengan situasi, keinginan, dan perubahan, (Kemendikbud, 2010), Kepramukaan adalah tahap pembentukan sikap, akhlak, dan pengamalan nilai kepramukaan. Kegiatan kepramukaan pada umumnya diselenggarakan diluar lingkungan sekolah dan lingkungan keluarga, yang mencakup kegiatan yang menyenangkan dan menarik yang dilakukan di alam terbuka dengan prinsip dasar kepramukaan dalam bentuk ekstrakulikuler, dan metode kepramukaan, yang sasaran akhirnya pembentukan karakter, (Afandi \& Rocmah, 2015).

Dunia pendidikan tidak terlepas dari yang namanya buku ajar, buku ajar merupakan sesuatu yang sangat diperlukan, perannya dalam setiap proses pembelajaran untuk menyajikan, sumber informasi, dan sumber kegiatan lainnya. Terlepas dari hal itu, buku ajar juga bermanfaat sebagai sumber referensi informasi kebahasaan. Berdasarkan hasil analisis kebutuhan terhadap mahasiswa 98\% permasalahan yang dihadapi para mahasiswa adalah minimnya referensi yang bisa dapat digunakan dalam proses pembelajaran. Permasalahan ini diperlukan suatu pengembangan buku ajar berbasis saintifik untuk mata kuliah pramuka. Buku ajar yang dikembangkan merupakan buku ajar penunjang yang mampu menunjukkan sumber informasi yang berbeda dengan yang ada. 
Menurut (Irwansyah \& Junaidi, 2019), Buku ajar yang bersifat sistematis yang disusun secara spesifik untuk mempermudah dalam mempelajarinya. Menurut (Pangastuti et al., 2016), buku ajar merupakan buku panduan yang digunakan dalam pembelajaran guna membantu mencapai tujuan pendidikan, selain itu buku ajar merupakan buku yang berisikan ilmu pengetahuan dari hasil analisis terhadap kurikulum dalam bentuk tulisan (Nuha et al., 2016) maupun buku ajar yang berbasis QR Code (Guntur \& Didik, 2019). Buku ajar merupakan buku panduan pembelajaran yang digunakan oleh siswa guna membantu mencapai tujuan pendidikan nasional (Pangastuti et al., 2016). Buku ajar merupakan salah satu sumber tertulis yang secara luas digunakan dan dipercaya baik oleh guru/dosen dan mahasiswa (Raditya \& I, 2020). Buku merupakan salah satu media pembelajaran yang sangat dibutuhkan dalam proses pembelajaran (Irwansyah, 2018). Buku ajar adalah sebuah karya tulis yang berbentuk buku dalam bidang tertentu (Setyawan, 2018).

Saintifik merupakan suatu pendekatan yang mengembangkan berbagai ranah yakni kognitif, psikomotor, dan afektif. Selain itu pendekatan saintifik dianggap mampu merubah paradigma lama, dimana pembelajaran yang biasanya berpusat kepada guru/dosen menjadi pembelajaran berpusat pada siswa. Peraturan mendikbud Republik Indonesia No. 65 tahun 2013 terkait standar proses dalam pembelajaran kurikulum 2013 dilaksanakan melalui pendekatan saintifik, dan ditegaskan pula dengan permendikbud RI. No. 81 huruf A yang menjelasakan proses pembelajaran terdiri dari 5 (lima) pengalaman pokok belajar meliputi: Mengamati, Menanya, Eksperimen, Mengasosiasikan, dan Mengkomunikasikan, (Ritonga, 2017). Literasi Saintifik adalah kemampuan seseorang menggunakan ilmu pengetahuan dalam memahami fenomena ilmiah dalam memecahkan suatu permasalahan, (Novili et al., 2016), dan menurut (Rusnilawati, 2016) siswa/mahasiswa dapat belajar aktif dalam membangun ilmu pengetahuan dalam proses pembelajaran melalui pendekatan saintifik. Pembelajaran dengan pendekatan saintifik lebih efektif hasilnya dibandingkan pembelajaran tradisional, (Yustitia et al., 2018). 


\section{METODE}

Penelitian ini merupakan penelitian pengembangan yang menggunakan metode Borg and Gall dalam (Winarno, 2011), yaitu 1) Analisis kebutuhan, 2) Perencanaan, 3) Desain produk, 4) Uji coba skala kecil, 5) Produk pertama direvisi, 6) Uji kelompok besar, 7) Revisi produk ke dua, 8) Uji lapangan, 9) Revisi ke tiga, dan 10) Diseminasi dan implementasi.

Penelitian dilaksanakan dengan beberapa tahap, tahap pengembangan produk buku ajar berbasis saintifik pada mata kuliah pramuka dilaksanakan pada bulan Januari 2020 s.d. bulan Desember 2020 di IKIP Budi Utomo Malang.

Untuk mengetahui validitas dan daya tarik produk maka perlu dilakukan uji coba produk. Beberapa tahap uji coba yaitu, uji coba ahli terdiri dari ahli isi (materi), ahli Bahasa Indonesia, ahli media pembelajaran dan uji coba terhadap pengguna buku ajar yaitu mahasiswa dengan tujuan untuk mengetahui tingkat validitas, daya tarik, dan keterbacaan buku ajar yang terbagi dalam tahap uji kelompok kecil sebanyak 10 mahasiswa, uji kelompok besar sebanyak 30 mahasiswa, dan uji lapangan sebanyak 50 mahasiswa sebagai subjek penelitian.

Hasil jawaban angket dari ahli dan mahasiswa, kemudian dianalisis dengan tujuan untuk mengetahui tentang buku ajar yang dikembangkan. Pengolahan data dihitung prosentase dari tiap butir pertanyaan dengan persamaan yang digunakan yaitu,

$$
K=\frac{F}{N \cdot I . R} X 100 \%
$$

Keterangan:

K : Persentase Kelayakan

F : Jumlah Jawaban Responden

$\mathrm{N}$ : Skor Tertinggi dalam Angket

I : Jumlah Pertanyaan dalam Angket

R : Jumlah Responden. 
Penafsiran dan penyimpulan hasil sesuai dengan kriteria kategori penilaian ideal dengan ketentuan yang terdapat pada Tabel 1 sebagai berikut:

Tabel 1. Kriteria Prosentase Respon Validator

\begin{tabular}{lll}
\hline \multicolumn{1}{c}{ Skor } & \multicolumn{1}{c}{ Keterangan } & \multicolumn{1}{c}{ Keputusan Uji } \\
\hline $0 \%-20 \%$ & Sangat Kurang Valid & Tidak layak dan perlu revisi besar \\
$21 \%-40 \%$ & Kurang Valid & Kurang layak dan perlu revisi besar \\
$41 \%-60 \%$ & Cukup Valid & Cukup layak dan perlu revisi besar \\
$61 \%-80 \%$ & Valid & Layak namun tetap dilakukan revisi kecil \\
$81 \%-100 \%$ & Sangat Valid & Sangat layak dan tidak revisi jika mencapai 100\% \\
\hline \multicolumn{2}{l}{ (Riduwan, 2003) }
\end{tabular}

\section{HASIL DAN PEMBAHASAN}

1. ValidasiAhli Isi (materi kepramukaan)

Uji coba ahli isi materi kepramukaan, sebagai Subjek uji coba dimohon menilai produk buku ajar kepramukaan dari segi isi (materi kepramukaan) pada angket. Hasil penilaian dari ahli isi (materi pramuka) disajikan pada tabel 2 berikut ini:

Tabel 2. Validasi ahli isi (materi pramuka)

\begin{tabular}{llc}
\hline No. & \multicolumn{1}{c}{ Kriteria } & Skor \\
\hline 1. & Ketepatan judul dengan materi buku ajar & 4 \\
2. & Isi buku sesuai dengan konsep saintifik & 4 \\
3. & Kesesuaian antar materi dan kurikulum yang berlaku & 3 \\
4. & Tujuan pembelajaran dan paparan materi sesuai & 4 \\
5. & Kejelasan pemaparan materi & 4 \\
6. & Kesesuaian antara gambar/ilustrasi dan materi & 3 \\
Jumlah & $\mathbf{2 2}$ \\
Prosentase \% & $\mathbf{9 1 , 6 7 \%}$ \\
\hline
\end{tabular}

Merujuk kepada tabel 2 dihitung prosentase penilaian ahli isi (materi kepramukaan) dengan skor 91,67\% (sangat valid) dan terdapat beberapa masukan dari ahli isi materi kepramukaan diantaranya 1) Akan lebih baik dibuatkan peta konsep pada awal bab agar lebih jelas materi yang disajikan pada tiap bab, 2) buatkan tes penilaian akhir bab.

2. Validasi Ahli Bahasa Indonesia

Dalam uji coba ini ahli bahasa Indonesia, sebagai Subjek uji untuk menilai produk buku ajar dalam segi bahasa Indonesia melalui angket. Hasil angket dimuat dalam tabel 3 berikut: 
Tabel 3. Penilaian ahli bahasa Indonesia

\begin{tabular}{llc}
\hline No. & \multicolumn{1}{c}{ Kriteria } & Skor \\
\hline 1. & Penggunaan bahasa & 4 \\
2. & Kejelasan huruf dan ukuran huruf & 4 \\
3. & Kejelasan penggunaan huru besar dan kecil & 3 \\
4. Kejelasan penggunaan tanda baca & 4 \\
5. Penggunaan paragraf & 4 \\
Jumlah & $\mathbf{1 9}$ \\
Prosentase \% & $\mathbf{9 5 \%}$ \\
\hline
\end{tabular}

Berdasarkan data pada tabel 3 dihitung prosentase penilaian ahli bahasa Indonesia dengan skor $95 \%$ (sangat valid) dan terdapat beberapa masukan diantaranya adalah masih ada beberapa penulisan kata-kata yang salah dan penggunaan huruf kapital harus lebih diperhatikan lagi.

3. Validasi ahli media pembelajaran

Penilaian pada unsur media pembelajaran pada buku ajar oleh ahli media pembelajaran. Dalam validasi media pembelajaran, sebagai subjek uji coba dimohon untuk menilai produk buku ajar dalam segi media pembelajaran melalui angket. Hasil angket disajikan pada tabel berikut:

Tabel 4. Penilaian Ahli Media Pembelajaran

\begin{tabular}{llc}
\hline No & \multicolumn{1}{c}{ Kriteria } & Skor \\
\hline $\mathbf{1}$ & Ketepatan ilustrasi yang digunakan dalam cover & 4 \\
$\mathbf{2}$ & Kesesuaian antara materi dan media yang digunakan & 4 \\
$\mathbf{3}$ & Kualitas gambar yang digunakan & 3 \\
$\mathbf{4}$ & Ketepatan ukuran dan penempatan gambar & 4 \\
$\mathbf{5}$ & Kualitas teks & 4 \\
Jumlah & $\mathbf{1 9}$ \\
Prosentase \% & $\mathbf{9 5 \%}$ \\
\hline
\end{tabular}

Berdasarkan pada tabel 4 dapat dihitung prosentase penilaian ahli media pembelajaran dengan skor 95\% (sangat valid). Terdapat beberapa masukan dari ahli media pembelajaran diantaranya masih ada beberapa gambar yang masih kurang jelas, Usahakan posisi gambar tepat dengan penjelasannya.

4. Uji coba kelompok kecil

Uji coba kelompok kecil mahasiswa yang menjadi subjek merupakan mahasiswa yang memprogram mata kuliah kepramukaan yang berjumlah 10 mahasiswa. Pada angket terdapat beberapa masukan dari mahasiswa: Gambar pada buku harus orang asli agar supaya menarik, Warna gambar kurang bagus. 
Hasil penilaian oleh mahasiswa melalui angket disajikan dalam tabel 5 sebagai berikut.

Tabel 5. Penilaian uji kelompok kecil

\begin{tabular}{ll}
\hline No & \multicolumn{1}{c}{ Kriteria } \\
\hline $\mathbf{1}$ & Bagaimanakah tampilan buku teks \\
$\mathbf{2}$ & Apakah ukuran dan jenis huruf yang digunakan dalam buku teks mudah dibaca \\
$\mathbf{3}$ & Bagaimanakah kejelasan paparan materi pada tiap bab dalam buku teks \\
$\mathbf{4}$ & Bagaimanakah tingkat kesesuaian antara gambar dan materi dalam buku \\
$\mathbf{5}$ & Bagaimana urutan penyajian materi pada tiap bab buku teks ini \\
\hline
\end{tabular}

\begin{tabular}{|c|c|c|c|c|c|c|c|c|c|c|}
\hline \multirow{2}{*}{ Kriteria } & \multicolumn{10}{|c|}{ Skor Siswa } \\
\hline & 1 & 2 & 3 & 4 & 5 & 6 & 7 & 8 & 9 & 10 \\
\hline 1 & 4 & 3 & 4 & 4 & 4 & 3 & 4 & 4 & 4 & 4 \\
\hline 2 & 4 & 4 & 4 & 3 & 4 & 4 & 4 & 3 & 4 & 4 \\
\hline 3 & 4 & 3 & 3 & 4 & 4 & 4 & 4 & 4 & 4 & 3 \\
\hline 4 & 4 & 4 & 4 & 4 & 4 & 3 & 4 & 3 & 4 & 4 \\
\hline 5 & 4 & 4 & 4 & 3 & 4 & 4 & 3 & 4 & 4 & 3 \\
\hline Jumlah & 20 & 18 & 19 & 18 & 20 & 18 & 19 & 18 & 20 & 18 \\
\hline$\%$ & $100 \%$ & $90 \%$ & $95 \%$ & $90 \%$ & $100 \%$ & $90 \%$ & $95 \%$ & $90 \%$ & $100 \%$ & $90 \%$ \\
\hline Rata-Rata \% & \multicolumn{10}{|c|}{$94 \%$} \\
\hline
\end{tabular}

Merujuk pada tabel 5 dihitung prosentase penilaian uji kelompok kecil dengan skor 94\% (sangat valid) dan terdapat masukan dari dari hasil uji coba kelompok kecil yaitu tampilan, dan perpaduan warna pada cover buku ajar masih kurang menarik.

5. Uji coba kelompok besar

Uji kelompok besar dengan sejumlah subjek 30 mahasiswa yang memprogram mata kuliah kepramukaan. Terdapat beberapa masukan dari mahasiswa: harus ada contoh kegiatan pembelajaran pada tiap bab, warna gambar kurang menarik. Hasil penilaian angket disajikan dalam Tabel 6 berikut:

Tabel 6. Penilaian uji kelompok besar

\begin{tabular}{ll}
\hline No & \multicolumn{1}{c}{ Kriteria } \\
\hline $\mathbf{1}$ & Bagaimanakah tampilan buku teks \\
$\mathbf{2}$ & Apakah ukuran dan jenis huruf yang digunakan dalam buku teks mudah dibaca \\
$\mathbf{3}$ & Bagaimanakah kejelasan paparan materi pada tiap bab dalam buku teks \\
$\mathbf{4}$ & Bagaimanakah tingkat kesesuaian antara gambar dan materi dalam buku \\
$\mathbf{5}$ & Bagaimana urutan penyajian materi pada tiap bab buku teks ini \\
\hline
\end{tabular}




\begin{tabular}{|c|c|c|c|c|c|c|c|c|c|c|}
\hline \multirow{2}{*}{ Kriteria } & \multicolumn{10}{|c|}{ Skor Siswa } \\
\hline & 1 & 2 & 3 & 4 & 5 & 6 & 7 & 8 & 9 & 10 \\
\hline 1 & 3 & 3 & 4 & 4 & 4 & 4 & 4 & 4 & 4 & 4 \\
\hline 2 & 4 & 4 & 3 & 4 & 4 & 4 & 4 & 3 & 4 & 4 \\
\hline 3 & 4 & 3 & 4 & 4 & 4 & 4 & 4 & 4 & 4 & 3 \\
\hline 4 & 4 & 4 & 4 & 4 & 4 & 3 & 4 & 3 & 3 & 4 \\
\hline 5 & 4 & 4 & 4 & 3 & 4 & 4 & 3 & 4 & 4 & 3 \\
\hline Jumlah & 19 & 18 & 19 & 19 & 20 & 19 & 19 & 18 & 19 & 18 \\
\hline$\%$ & $95 \%$ & $90 \%$ & $95 \%$ & $95 \%$ & $100 \%$ & $95 \%$ & $95 \%$ & $90 \%$ & $95 \%$ & $90 \%$ \\
\hline \multirow{2}{*}{ Kriteria } & \multicolumn{10}{|c|}{ Skor Siswa } \\
\hline & 11 & 12 & 13 & 14 & 15 & 16 & 17 & 18 & 19 & 20 \\
\hline 1 & 3 & 3 & 4 & 4 & 4 & 3 & 4 & 4 & 4 & 4 \\
\hline 2 & 4 & 4 & 3 & 3 & 4 & 3 & 4 & 3 & 4 & 4 \\
\hline 3 & 4 & 4 & 4 & 4 & 4 & 4 & 4 & 4 & 4 & 4 \\
\hline 4 & 3 & 4 & 4 & 4 & 4 & 4 & 4 & 4 & 4 & 4 \\
\hline 5 & 4 & 4 & 4 & 3 & 4 & 4 & 3 & 4 & 4 & 4 \\
\hline Jumlah & 18 & 19 & 19 & 18 & 20 & 18 & 19 & 19 & 20 & 20 \\
\hline$\%$ & $90 \%$ & $95 \%$ & $95 \%$ & $90 \%$ & $100 \%$ & $90 \%$ & $95 \%$ & $95 \%$ & $100 \%$ & $100 \%$ \\
\hline \multirow{2}{*}{ Kriteria } & \multicolumn{10}{|c|}{ Skor Siswa } \\
\hline & 21 & 22 & 23 & 24 & 25 & 26 & 27 & 28 & 29 & 30 \\
\hline 1 & 4 & 4 & 4 & 4 & 4 & 3 & 4 & 4 & 4 & 4 \\
\hline 2 & 4 & 4 & 4 & 3 & 4 & 4 & 4 & 4 & 4 & 4 \\
\hline 3 & 4 & 3 & 3 & 4 & 4 & 4 & 4 & 4 & 4 & 4 \\
\hline 4 & 3 & 4 & 4 & 4 & 4 & 3 & 4 & 3 & 3 & 4 \\
\hline 5 & 4 & 4 & 4 & 4 & 4 & 4 & 3 & 4 & 4 & 3 \\
\hline Jumlah & 19 & 19 & 19 & 19 & 20 & 18 & 19 & 19 & 19 & 19 \\
\hline$\%$ & $95 \%$ & $95 \%$ & $95 \%$ & $95 \%$ & $100 \%$ & $90 \%$ & $95 \%$ & $95 \%$ & $95 \%$ & $95 \%$ \\
\hline Rata-Rata \% & \multicolumn{10}{|c|}{$94,5 \%$} \\
\hline
\end{tabular}

Berdasarkan data pada tabel 6 dihitung prosentase penilaian uji kelompok besar dengan skor 94,5\% (sangat valid) dan terdapat masukan diantaranya adalah masih ada beberapa penulisan kata yang salah dan dan ukuran huruf terlalu kecil. 6. Uji Lapangan

Uji lapangan dibutuhkan 50 subjek mahasiswa yang memprogram mata kuliah kepramukaan. Pada hasil pengisian angket terdapat beberapa masukan dari mahasiswa: Hasil penilaian mahasiswa dimuat dalam tabel 7 berikut:

Tabel 7. Penilaian uji lapangan

\begin{tabular}{ll}
\hline No & \multicolumn{1}{c}{ Kriteria } \\
\hline $\mathbf{1}$ & Bagaimanakah tampilan buku teks \\
$\mathbf{2}$ & Apakah ukuran dan jenis huruf yang digunakan dalam buku teks mudah dibaca \\
$\mathbf{3}$ & Bagaimanakah kejelasan paparan materi pada tiap bab dalam buku teks \\
$\mathbf{4}$ & Bagaimanakah tingkat kesesuaian antara gambar dan materi dalam buku \\
$\mathbf{5}$ & Bagaimana urutan penyajian materi pada tiap bab buku teks ini \\
\hline
\end{tabular}




\begin{tabular}{|c|c|c|c|c|c|c|c|c|c|c|}
\hline \multirow{2}{*}{ Kriteria } & \multicolumn{10}{|c|}{ Skor Siswa } \\
\hline & 1 & 2 & 3 & 4 & 5 & 6 & 7 & 8 & 9 & 10 \\
\hline 1 & 4 & 4 & 4 & 4 & 4 & 4 & 4 & 4 & 4 & 4 \\
\hline 2 & 4 & 4 & 3 & 4 & 4 & 3 & 4 & 3 & 4 & 4 \\
\hline 3 & 4 & 3 & 4 & 4 & 4 & 4 & 4 & 4 & 4 & 4 \\
\hline 4 & 4 & 4 & 4 & 4 & 4 & 3 & 4 & 3 & 3 & 4 \\
\hline 5 & 4 & 4 & 4 & 3 & 4 & 4 & 3 & 4 & 4 & 3 \\
\hline Jumlah & 20 & 19 & 19 & 19 & 20 & 18 & 19 & 18 & 19 & 19 \\
\hline$\%$ & $100 \%$ & $95 \%$ & $95 \%$ & $95 \%$ & $100 \%$ & $90 \%$ & $95 \%$ & $90 \%$ & $95 \%$ & $95 \%$ \\
\hline \multirow{2}{*}{ Kriteria } & \multicolumn{10}{|c|}{ Skor Siswa } \\
\hline & 11 & 12 & 13 & 14 & 15 & 16 & 17 & 18 & 19 & 20 \\
\hline 1 & 4 & 3 & 4 & 4 & 4 & 3 & 4 & 4 & 4 & 4 \\
\hline 2 & 4 & 4 & 3 & 3 & 4 & 3 & 4 & 4 & 4 & 4 \\
\hline 3 & 4 & 4 & 4 & 4 & 4 & 4 & 4 & 4 & 4 & 4 \\
\hline 4 & 4 & 4 & 4 & 4 & 4 & 4 & 4 & 4 & 4 & 4 \\
\hline 5 & 4 & 4 & 4 & 3 & 4 & 4 & 3 & 4 & 4 & 4 \\
\hline Jumlah & 20 & 19 & 19 & 18 & 20 & 18 & 19 & 20 & 20 & 20 \\
\hline$\%$ & $100 \%$ & $95 \%$ & $95 \%$ & $90 \%$ & $100 \%$ & $90 \%$ & $95 \%$ & $100 \%$ & $100 \%$ & $100 \%$ \\
\hline \multirow{2}{*}{ Kriteria } & \multicolumn{10}{|c|}{ Skor Siswa } \\
\hline & 21 & 22 & 23 & 24 & 25 & 26 & 27 & 28 & 29 & 30 \\
\hline 1 & 4 & 4 & 4 & 4 & 4 & 3 & 4 & 4 & 3 & 4 \\
\hline 2 & 4 & 4 & 4 & 3 & 4 & 4 & 4 & 4 & 4 & 4 \\
\hline 3 & 4 & 3 & 4 & 4 & 4 & 4 & 4 & 4 & 4 & 4 \\
\hline 4 & 4 & 4 & 3 & 4 & 4 & 3 & 4 & 3 & 3 & 4 \\
\hline 5 & 4 & 4 & 4 & 4 & 4 & 4 & 3 & 4 & 4 & 3 \\
\hline Jumlah & 20 & 19 & 19 & 19 & 20 & 18 & 19 & 19 & 18 & 19 \\
\hline$\%$ & $100 \%$ & $95 \%$ & $95 \%$ & $95 \%$ & $100 \%$ & $90 \%$ & $95 \%$ & $95 \%$ & $90 \%$ & $95 \%$ \\
\hline \multirow{2}{*}{ Kriteria } & \multicolumn{10}{|c|}{ Skor Siswa } \\
\hline & 31 & 32 & 33 & 34 & 35 & 36 & 37 & 38 & 39 & 40 \\
\hline 1 & 3 & 4 & 4 & 4 & 4 & 3 & 4 & 4 & 3 & 4 \\
\hline 2 & 4 & 3 & 3 & 3 & 3 & 4 & 4 & 4 & 4 & 4 \\
\hline 3 & 4 & 3 & 4 & 4 & 4 & 4 & 4 & 4 & 3 & 3 \\
\hline 4 & 4 & 4 & 3 & 4 & 4 & 3 & 3 & 3 & 3 & 4 \\
\hline 5 & 4 & 4 & 4 & 4 & 4 & 4 & 3 & 4 & 4 & 3 \\
\hline Jumlah & 19 & 18 & 18 & 19 & 19 & 18 & 18 & 19 & 17 & 18 \\
\hline$\%$ & $95 \%$ & $90 \%$ & $90 \%$ & $95 \%$ & $95 \%$ & $90 \%$ & $90 \%$ & $95 \%$ & $85 \%$ & $90 \%$ \\
\hline \multirow{2}{*}{ Kriteria } & \multicolumn{10}{|c|}{ Skor Siswa } \\
\hline & 41 & 42 & 43 & 44 & 45 & 46 & 47 & 48 & 49 & 50 \\
\hline 1 & 4 & 4 & 4 & 4 & 4 & 3 & 4 & 4 & 4 & 4 \\
\hline 2 & 4 & 4 & 4 & 3 & 4 & 4 & 4 & 4 & 4 & 4 \\
\hline 3 & 4 & 4 & 3 & 4 & 4 & 4 & 4 & 4 & 4 & 4 \\
\hline 4 & 4 & 4 & 4 & 4 & 3 & 4 & 4 & 4 & 4 & 4 \\
\hline 5 & 4 & 4 & 4 & 4 & 4 & 4 & 3 & 4 & 4 & 3 \\
\hline Jumlah & 20 & 20 & 19 & 19 & 19 & 19 & 19 & 20 & 20 & 19 \\
\hline$\%$ & $100 \%$ & $100 \%$ & $95 \%$ & $95 \%$ & $95 \%$ & $95 \%$ & $95 \%$ & $100 \%$ & $100 \%$ & $95 \%$ \\
\hline Rata-Rata $\%$ & \multicolumn{10}{|c|}{$95 \%$} \\
\hline
\end{tabular}


Berdasarkan pada tabel 7 dapat dihitung prosentase penilaian dari hasil uji lapangan dengan skor 95\% (sangat valid) dalam artian buku ajar sangat layak digunakan sebagai media penunjang dalam proses pembelajaran mata kuliah kepramukaan.

\section{PEMBAHASAN}

Penyajian analisis data dan revisi terhadap pengembangan produk buku ajar menjadi fokus pembahasan. Hasil penilaian ahli materi kepramukaan bila dikonversikan pada tabel mencapai skala 4 dengan kualifikasi baik ini menunjukkan bahwa buku ajar perlu direvisi secukupnya. Revisi yang dilakukan terhadap buku ajar berdasarkan masukan dari ahli isi adalah sebagai berikut: Akan lebih baik dibuatkan peta konsep pada awal bab agar lebih jelas materi yang di sajikan ditiap bab buatkan tes penilaian pada akhir bab.

Penilaian ahli bahasa Indonesia terhadap produk buku ajar melalui jawaban angket dengan prosentase sebesar 95\%. Bila dikonversikan dalam tabel mencapai skala 4 berada pada kualifikasi baik dalam artian buku ajar perlu revisi sedikit. Adapun revisi yang dianjurkan terhadap buku ajar berdasarkan masukan ahli bahasa Indonesia yaitu masih ada beberapa penulisan kata-kata yang salah dan penggunaan huruf kapital harus lebih diperhatikan lagi.

Hasil penilaian ahli media pembelajaran dengan prosentase sebesar $95 \%$ dengan kualifikasi baik, bila dikonversikan pada tabel tingkat pencapaian skala 4 dengan kualifikasi baik, ini berarti buku ajar memerlukan sedikit revisi. Adapun beberapa revisi yang bisa dilakukan terhadap buku ajar berdasarkan masukan dari ahli media pembelajaran diantaranya masih ditemukan gambar yang kurang jelas, dan usahakan posisi gambar tepat dengan penjelasannya.

Subjek uji kelompok kecil adalah 10 mahasiswa dan hasil analisis deskriptif prosentase buku ajar sebesar 94\% dengan kualifikasi baik dan buku ajar perlu revisi sedikit, uji coba kelompok besar adalah 30 mahasiswa dengan kemampuan tinggi, sedang dan rendah hasil analisis statistik deskriptif berada pada prosentase sebesar 94,5\% dengan kualifikasi baik dan buku ajar perlu ada sedikit revisi, sesuai saran dan masukan oleh mahasiswa dan sedangkan untuk uji lapangan sebanyak 50 mahasiswa yang menjadi subjek dengan tingkat kemapuan 
yang bervariasi, hasil analisis statistik deskriptif prosentase buku ajar sebesar 95\% dengan kualifikasi baik sehingga buku ajar boleh digunakan. Adapun beberapa penelitian yang terkait diantaranya penelitian yang dilakukan oleh (Yulia Khairuna, 2020), Pengembangan Bahan Ajar Berbasis Saintifik menunjukkan hasil masuk dalam kategori baik yang sesuai dengan karakteristik kurikulum 2013. (Amin Farozi, 2014) dengan judul buku saku gerakan pramuka dengan hasil buku saku pramuka ini bermanfaat untuk kemajuan dan pengembangan pramuka indonesia dalam artian kategori sangat baik. (Septiani 2012) dengan judul pengembangan paket buku saku pramuka yang menghasilkan buku saku yang dapat digunakan untuk meningkatkan keterampilan khususnya untuk penggalang ramu.

\section{SIMPULAN}

Dihasilkan buku ajar berbasis saintifik mata kuliah kepramukaan dengan prosentase validitas dari ahli isi sebesar 91,67\%, (sangat valid), ahli Bahasa Indonesia 95\% (Sangat Valid), ahli media pembelajaran sebesar 95\% (sangat valid), Uji coba kelompok kecil dengan skor 94\% (sangat valid), Uji coba kelompok besar dengan skor 94,5\% (sangat valid), dan Uji lapangan sebesar 95\% (sangat valid), berarti buku ajar berkualifikasi "Sangat layak" digunakan.

\section{DAFTAR RUJUKAN}

Afandi, R., \& Rocmah, L. I. (2015). Pramuka Sebagai Wadah Mengembangkan Life Skill Mahasiswa Calon Guru Pada Perguruan Tinggi LPTK. PEDAGOGIA: Jurnal Pendidikan, 4(2), 135-140.

Cahyono, B., Tsani, D., \& Rahma, A. (2018). Pengembangan Bahan Ajar Buku Saku Matematika Berbasis Pendidikan Karakter Materi Trigonometri. Phenomenon: Jurnal Pendidikan Mipa, 8(2), 185-199.

Farozi, A. (2014). Aplikasi Buku Saku Gerakan Pramuka Bilingual Berbasis Android (Doctoral dissertation, Universitas Muhammadiyah Surakarta).

Firmansyah, G., \& Hariyanto, D. (2019). Penggunaan kode QR pada domain pendidikan: penelitian dan pengembangan bahan ajar. Jurnal SPORTIF: Jurnal Penelitian Pembelajaran, 5 (2), 265-278.

Irwansyah, I. (2018). Pengembangan Buku Ajar Teori Tenis Meja Bagi Mahasiswa Kelas A 2016 Jurusan PJKR IKIP BUDI Utomo Malang. Jp. jok (Jurnal Pendidikan Jasmani, Olahraga dan Kesehatan), 1(2), 47-59. 
Irwansyah, I., \& Junaidi, A. (2019). Pengembangan Buku Ajar Berbasis Praktek Pada Mata Kuliah Tenis Lapangan Di Ikip Budi Utomo. Journal Sport Area, 4(2), 348. Https://doi.org/10.25299/sportarea.2019.vol4(2).3857

Kemendikbud. (2010). Undang-Undang No. 12 Tahun 2010 Tentang Gerakan Pramuka. Kementrian Pendidikan dan Kebudayaan Republik Indonesia.

Muhaemin, M., \& Ihwah, A. (2019). Pengaruh Pendidikan Pramuka Terhadap Pembentukan Karakter Religius pada Anggota Pramuka. al-Iltizam: Jurnal Pendidikan Agama Islam, 4(1), 111-120.

Novili, W. I., Utari, S., \& Saepuzaman, D. (2016). Penerapan Scientific Approach untuk Meningkatkan Literasi Saintifik dalam Domain Kompetensi Siswa SMP pada Topik Kalor. Jurnal Penelitian \& Pengembangan Pendidikan Fisika, 2(1), 51-56.

Nuha, U., Amin, M., \& Lestari, U. (2016). Pengembangan buku ajar berbasis penelitian evolusi dan filogenetik molekuler untuk mata kuliah evolusi di Universitas Jember. Jurnal Pendidikan: Teori, Penelitian, dan Pengembangan, 1(9), 1791-1796.

Pangastuti, A., Amin, M., \& Indriwati, S. I. (2016). Pengembangan Buku Ajar Biologi Sel Dengan Pendekatan Bioinformatika. Jurnal Pendidikan: Teori, Penelitian, dan Pengembangan, 1(4), 127-132.

Raditya, A., \& Iskandar, R. S. F. (2020). Analisis Soal PLSV pada Buku Ajar Matematika dari Kurikulum 1994 hingga Kurikulum 2013. Phenomenon: Jurnal Pendidikan MIPA, 9(2), 232-145.

Riduwan. (2003). Dasar-Dasar Statistika. Bandung: Alfabeta.

Ritonga, A. A. (2017). Pendekatan Saintifik Pembelajaran Pendidikan Agama Islam Pada Sekolah Dasar Islam Terpadu. MIQOT: Jurnal Ilmu-ilmu Keislaman, 41(1).

Rusnilawati, R. (2016). Pengembangan perangkat pembelajaran matematika bercirikan active knowledge sharing dengan pendekatan saintifik kelas VIII. Jurnal Riset Pendidikan Matematika, 3(2), 245-258.

Septiani, M. (2012). Paket Buku Saku Pramuka Penggalang Ramu. Perspektif Ilmu Pendidikan, 25(XVI), 62-72.

Setyawan, T. (2018). Pengembangan Buku Ajar Pendidikan Jasmani Dan Olahraga Melalui Pendekatan Saintifik Kelas Iv Sdn Nguter 02 Lumajang. Jp. Jok (Jurnal Pendidikan Jasmani, Olahraga Dan Kesehatan), 1(2), 24-46.

Winarno, M. E. (2011). Metodologi penelitian dalam pendidikan jasmani. Media Cakrawala Utama Press, Malang.

Khairuna, Y. (2020). Pengembangan Bahan Ajar Berbasis Saintifik Jenjang SD/MI Kelas III Tema 8 "Praja Muda Karana" Subtema 2 "Aku Anak Mandiri” (Doctoral dissertation, UIN Ar-Raniry Banda Aceh). 
Yustitia, V., Rusminati, S. H., \& Sulistyawati, I. (2018). Penerapan model think pair share dengan pendekatan saintifik melalui lesson study pada mata kuliah evaluasi pembelajaran SD. Premiere Educandum: Jurnal Pendidikan Dasar Dan Pembelajaran, 8 (1), 88. 